\title{
Molecular and Functional Basis of Cystic Fibrosis in Indian Patients: Genetic, Diagnostic and Therapeutic Implications
}

\author{
Rajendra Prasad \\ Department of Biochemistry, \\ Postgraduate Institute of Medical Education and Research, \\ Chandigarh, India.
}

\begin{abstract}
Cystic fibrosis (CF, MIM\#219700) is a common autosomal recessive disorder among Caucasians, which was considered as rare disease for Indian population. CF is caused due to presence of mutations in the cystic fibrosis transmembrane conductance regulator (CFTR) gene. In this study, we established a spectrum of mutations from both classical CF as well as from infertile male patients with congenital absence of vas deferens (CAVD). In Indian classical CF patients, we reported 14 previously known and eight novel mutations, viz. 3986-3987 delC, 876-6 del4, 1792 InsA, L69H, S158N, Q493L, 1530L and E1329Q. The frequency of delta 508 was found to be $27 \%$. Absolute linkage between delta 508 and KM19-GATT TUB9-M470V-T854T haplotype predicts a relatively recent appearance of delta 508 mutations in Indian population. The CFTR gene analysis in CAVD infertile males documented 13 different CFTR gene mutations and 1 intronic variant that led to aberrant splicing. P.Phe $508 \mathrm{del}(\mathrm{n}=16)$ and p.Arg 117 His $(\mathrm{n}=4)$ were among the common severe forms of CFTR mutations identified. The IVS-8-T5 allele (mild form of mutations) was formed with an allele frequency of $28.3 \%$. Eight novel mutations were also found in the CFTR gene from our patient cohort. We also investigated whether genetic modifiers, viz. transforming growth factor (TGF- $\beta$ ) and endothelial receptor type A (EDNRA) of CF lung disease also predispose to CAVD in association with CFTR mutations, which were associated with the CAVD phenotype.
\end{abstract}

Functional characterization of identified 11 novel CFTR gene mutations disclosed that a significant reduction in channel activity for $L 69 H$ and $S 549 N$ mutants in CFTR expressing cells was observed whereas impaired CFTR protein maturation was noticed only in $L 69 H$ substitute CFTR. CFTR correctors $(V X 809)$ rescued the defect due to $L 69 H$ mutation, which is evidenced from detection of C band in $L 69 H$ mutant expressing cells pre-treated with $V X 809$. The chloride channel activity in $S 549 N$ and $L 69 H$ mutant $C F T R$ was also restored in presence of CFTR potentiators $V X 770$.

Above findings confirms heterogeneity of CFTR mutations in Indian classical and non-classical CF patients. They may help in developing a strategy to develop counseling and therapeutic approach for CF patients in India.

Keywords: Cystic fibrosis, genetic mutation, CFTR.

Correspondence: Dr. Rajendra Prasad, Former Professor \& Head, Department of Biochemistry, Postgraduate Institute of Medical Education and Research, Chandigarh-160012. Mob: +919417401134.Email: fateh1977@yahoo.com.

DR. V.R. KHANOLKAR ORATION delivered during the NAMSCON 2018 held at the Mahatma Gandhi Medical College \& Research Institute, Puducherry. 


\section{Introduction}

Cystic fibrosis (CF MIM\#219700) is the most common lethal autosomal recessive monogenic disease in Caucasian population with an average prevalence of one in 2500 live birth with carrier frequency 1 in 25 individuals (1). Notwithstanding, CF is still thought to be very rare in Indian population (2). However, published reports indicate that $\mathrm{CF}$ is probably far more common in people of Indian origin than previously thought but is underdiagnosed or missed in majority of cases. Dr. Bhakoo reported first case of CF in 1968 from PGIMER, Chandigarh (3). Later, we estimated the relative frequencies of various genetic disorders, which were found, with $7.56 \%$ frequency (4). The mutations in the $\mathrm{CF}$ transmembrane conductance regulator gene (CFTR or $A B C C 7$; MIM \# 602421), which are responsible for both classic and non-classic presentation of the disease (CAVD, MIM \# 22180) $(5,6)$. The CFTR gene was identified and cloned about two decades ago $(7,8)$. The CFTR gene is located on the long arm of chromosome 7 (region q31 q32) encompassing $250 \mathrm{~kb}$ and comprising 27 exons (7-9). It encodes a trans-membrane protein of 1480- amino acids that function as a CAMP- regulated chloride channel in exocrine epithelia (10). Hydropathy plot analysis disclosed that CFTR protein composed of two motifs, each containing a membrane spaning domain (MSD) that is composed of six tansmembrane helices and nucleotide binding domain (NBD) that contains sequence predicted to interact with ATP (II). MSD-NBD motifs are linked by a unique domain termed as regulatory domain ( $R$ ) that contains multiple phosphorylation sites and many charged amino acids. The carbonyl terminal, consisting of threonine, arginine, and leucine (TRL) which is anchored through a PDZ type - binding interaction with the cytoskeleton $(11,12)$ (Fig. $1)$.

More than 2000 sequence variants have been identified in the CFTR gene (http/www.genet.sickkids.on.cafchrome.html) and many of them have been implicated in a variety of CFTR related pathologic conditions such as respiratory distress, pancreatic insufficiency, meconium ileus and congenital absence of the vas deferens (CAVD) (13). Delta $508 F$ is the most common CFTR mutation

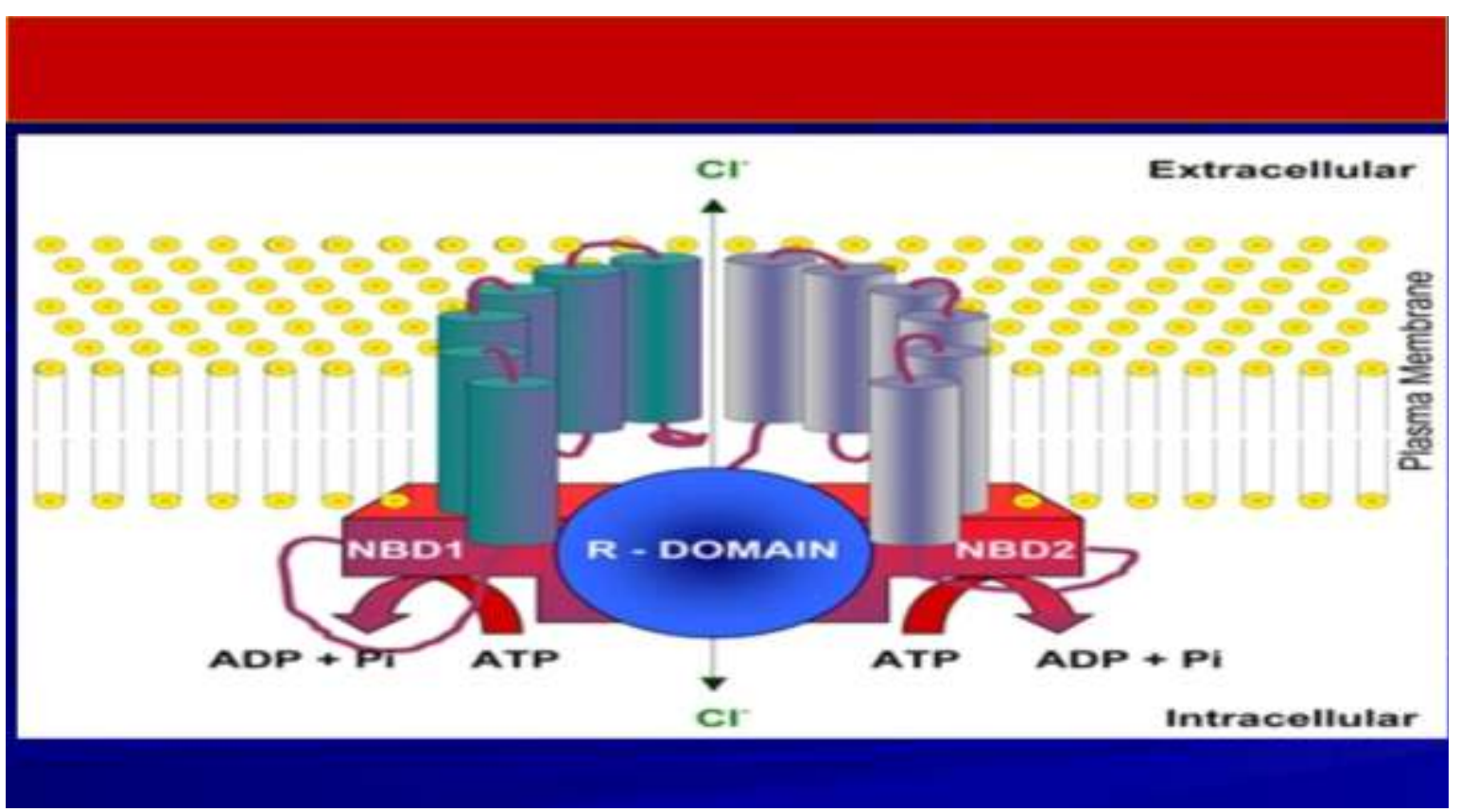

Fig.1: Hypothesized structure of CFTR showing proposed structure of CFTR protein. 
worldwide, which is present upto $92 \%$ of patients with CF. However, this frequency varies among countries and ethnic groups (http://www.cftrscience.com). All these mutations are classified into six classes based on the mechanism of the disruption of CFTR (14) and the absence of the CFTR protein at the apical plasma membrane which include defective protein synthesis, impaired protein maturation leading to protein degradation, defective regulation of CFTR channel activity, altered ionic selectivity and conductance, lowered CFTR mRNA amount and decreased protein stability.

CAVD is characterized as an isolated urogenital form of $\mathrm{CF}$ which is associated with normal spermatogenesis, but absence of sperm in the ejaculate due to lack of vas deferens (15). More than $95 \%$ of males with CF are infertile due to obstructive azoospermia caused by absent, atrophic or fibrotic Wolffian duct structure (16). The $p$. Phe $508 \mathrm{del}, \mathrm{p}$. Arg $117 \mathrm{H}$ is and $T 5$ allele were identified as most common CFTR mutations in caucassians associated with CAVD phenotype $(16,17)$. Despite advances in understanding the pathophysiology of $\mathrm{CF}$, there are still many inexplicable differences in its clinical association with CAVD. The role of intensifying the severity of classical CF is well established $(17,18)$. Transforming growth factor (TGF $\beta$ ), codon 10 polymorphism (rs180470) and codon 25 polymorphism (rs1800471) as well as endothelial receptor typeA $(E D N R A)$ gene polymorphism have been previously established in enhancing the severity of classical CF (17, 19). Molecularly, established mutations including preferentially novel and rare mutations is urgently needed for functional characterization at cellular level, so that, therapeutic molecules could be developed to target underlying molecular defect. Additionally, the cellular and functional data on theses mutations can improve CF genetic counseling. Recent advances of targeted molecular therapies and high throughput screening have resulted in multiple drug therapies that target many important mutations in the CFTR protein (20).

In this manuscript, we provide the work done on $\mathrm{CF}$ at Postgraduate Institute of Medical Education and Research, Chandigarh with special reference to its diagnostic and molecular characterization of spectrum of mutations from both classical and non-classical forms of CF. Haplotype association have been used to trace the origin and age of different $\mathrm{CF}$ mutations worldwide (21). There is no information available in this regard from Indian subcontinent. Therefore, haplotype study was also carried out using associated intragenic and extragenic marker haplotypes. The study was also performed to investigate whether genetic modifiers of CF lung disease also predispose to CAVD in association with CFTR mutations. We also provide the latest results and current progress of CFTR modulators for the treatment of cystic fibrosis, focusing on potentiators of CFTR channel gating and p.Phe508del CFTR mutation. Special emphasis is placed on the molecular basis of understanding these new therapies.

\section{Molecular Diagnosis of Cystic Fibrosis and its Underlying Pathogenesis}

The diagnosis of CF has vast implications for patients and their families. The broad spectrum of clinical disease and reports of over 2,000 different mutations have made the $\mathrm{CF}$ diagnosis difficult (22). The guidelines for $\mathrm{CF}$ diagnosis were established by the Cystic Fibrosis Foundation for diagnosis of both infants with positive newborn screening (NBS) findings and older patients presenting with an indistinct clinical picture. CF Foundation proposed the following diagnostic algorithm state: the diagnosis of CF should be based on the presence of one or more characteristic clinical features viz. respiratory, gastrointestinal or gastrourinary symptom, a history of CF in a sibling or a positive NBS test, plus laboratory evidence of an abnormality in the CFTR gene or protein (23, 24). Either biological evidence of channel dysfunction such as an abnormal sweat chloride 
test or nasal potential difference and identification of $\mathrm{CF}$ disease causing mutation on each allele of the CFTR gene are acceptable evidence of a CFTR abnormality. Newborn screening depends on initial analysis of fetal blood for high values of immunoreactive trypsinogen (IRT) followed by genetic testing or repeat (25).

The sweat chloride test remains the initial test of choice and gold standard for CF diagnosis despite its limitations. Sweat chloride test was developed by Gibson-Cooke in 1959 (25). The test is performed via pilocarpine inotophoresis, which is used to stimulate sweat gland secretion. The sweat is collected and analyzed for chloride concentration. The underlying mechanism of elevated levels of sweat sodium was demonstrated by Roeve et al (26) (Fig. 2).

Sweat chloride concentration above 60 mmol per liter $(>70 \mathrm{mmol} / \mathrm{L}$ in adolescent and adults) is suggestive of cystic fibrosis. In normal individuals and carriers of the CF gene, the mean sweat chloride concentrations are $30 \mathrm{mmol} / \mathrm{L}$.
Cut-off value for infants is $30 \mathrm{mmol} / \mathrm{L}$ (27). A positive sweat test is diagnostic as long as it is performed on adequate amount of sweat $(>100 \mathrm{mg})$ in CF. A second test for CFTR function such as nasal potential difference measurement or analysis of rectal mucosal biopsy is recommended if sweat test is equivocal (28).

DNA analysis in establishing CF diagnosis is most useful for those individuals with sweat chloride values in the intermediate range. Two or more disease causing CFTR mutations should be located on different alleles as $\mathrm{CF}$ is an autosomal recessive disease. $\mathrm{CF}$ Foundation recommends testing for the $23 \mathrm{CF}$ mutation panel developed by the American College of Medical Genetics (ACMG). These mutations have been demonstrated to cause sufficient loss of CFTR function to confer CF disease and are therefore noted as conclusive genetic evidence for diagnosis of CF (23). Indirect non-invasive parameters available for assessing the pancreatic function test are serum immunoreactive trypsin (IRT), fecal chymotrypsin, stool immunoreactive human

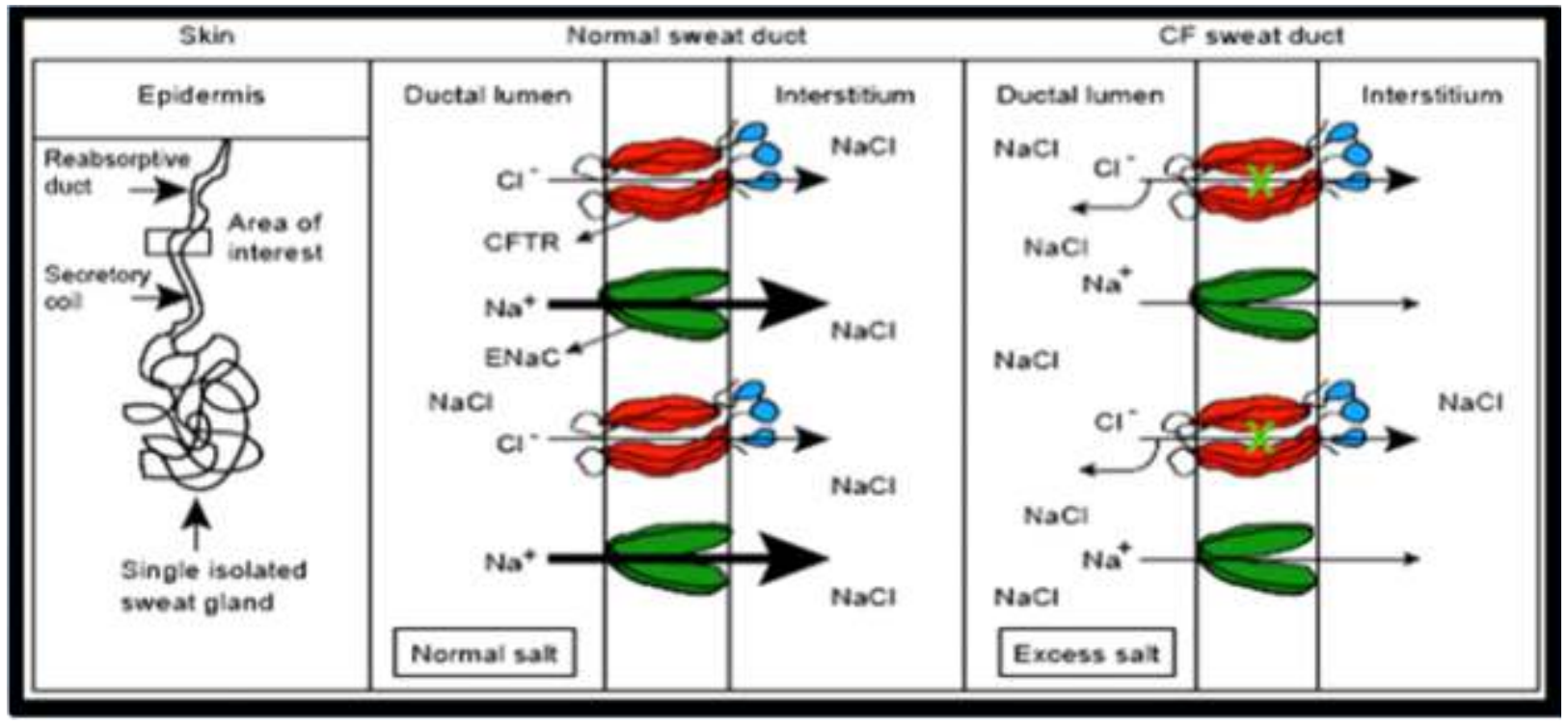

Fig.2: Mechanism understanding elevated sodium and chloride levels in the sweat of CF patients. Left panel shows cartoon of a sweat gland with sweat duct projecting out of the sweat gland through dermis into the epidermis. Middle panel shows role of CFTR and ENaC in maintaining normal salt concentration in sweat. Last panel shows dysfunctional CFTR leading to elevated salt concentration in sweat. 
lipase and stool fat excretion as a gold standard (29).

\section{Spectrum of Mutations in Classical Cystic Fibrosis}

A prospective cohort study was designed to establish a spectrum of mutations in CFTR gene. In this study, 1005 suspected CF subtypes were subjected for sweat chloride measurement. Notably, 45 subjects were diagnosed as CF on the basis of classical clinical phenotype and elevated sweat chloride. On the basis of clinical symptoms and autopsy reports that confirmed the diagnosis of $\mathrm{CF}$ in three patients with normal sweat chloride were also included. Besides, 2 infants with raised IRT were included as CF subjects.

Demographics and family history of CF subjects revealed that average age at diagnosis in CF subjects was 62.8 months compared to 9.3 months at age of presentation. Male to female ratio was 35.15. Notwithstanding, females had a higher median age at diagnosis (33 months) as compared to males (18 months). History of previous sib death due to respiratory or gastrointestinal problems was observed in 9 families. Consanguinity was noticed in three and history of similar gastrointestinal or respiratory complaints was recorded in another 4 families.
In 1 case, the patient's mother had a history of chronic pancreatitis and diabetes (30).

\section{Clinical Findings}

The usual presentations include failure to thrive $(94 \%)$, malabsoption $(82 \%)$, chronic cough $(90 \%)$, recurrent or persistent pneumonia $(79 \%)$ and meconium ileus $(10 \%)$. Mean Schwachman-Kidczyski score was $57.34 \pm 12.07$. The median age of CF patients with P.aeruginosa colonization was 39 months compared to 8 months with S.aureus. Pancreatic insufficiency was present in 37 patients $(77 \%)$. Mean IRT levels in CF patients were $176.43 \pm 141.23 \mathrm{ug} / \mathrm{L}$. Determination of fecal fat revealed steatorrhoea $(7.36 \pm 4.56 \mathrm{~g} / 24 \mathrm{~h})$ in 8 patients out of 15 tested $(53.33 \%)$. Notably, all patients with liver disease $(n=6)$ and meconium ileus $(n=5)$ had pancreatic insufficiency.

\section{Sweat Chloride}

Median sweat chloride value in $\mathrm{CF}$ subjects was $86.25 \mathrm{mEq} / \mathrm{L}$. All individual patient values were mean of two/three repeat sweat chloride estimation on different days. Amount of sweat chloride collected was more than $100 \mathrm{mg}$ on each occasion $(198 \pm 30 \mathrm{mg})$. In 2 infants, adequate sweat could not be collected. Fig. 3 shows individual sweat chloride values of CF ( $\mathrm{n}$

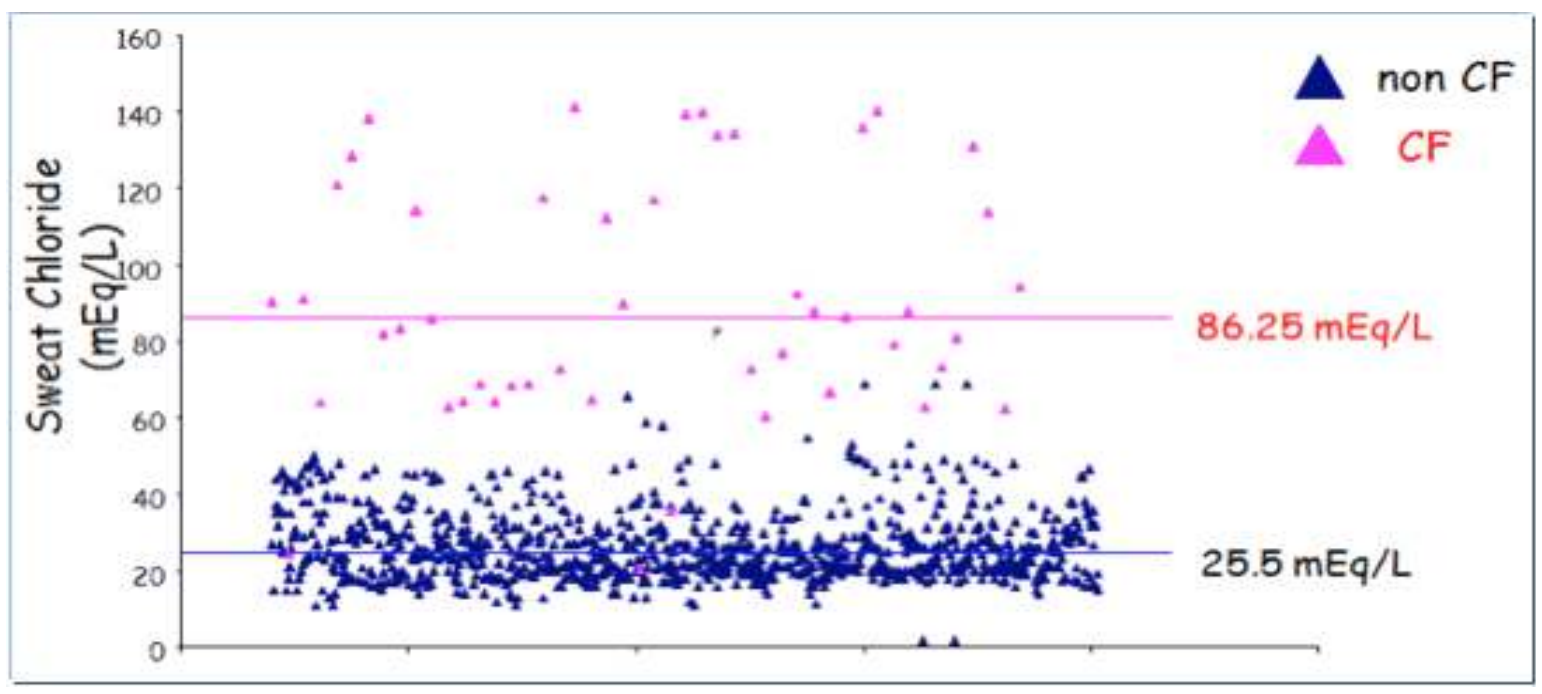

Fig.3: Comparison of sweat chloride values between $\mathrm{CF}$ and non-CF cases. 
$=48)$ and non-CF $(\mathrm{n}=956)$ subjects. Median sweat chloride value of $86.25 \mathrm{mEq} / \mathrm{L}$ in $\mathrm{CF}$ was significantly elevated as compared to 25.5 $\mathrm{meq} / \mathrm{L}$ in non-CF individuals. In India, there are only few centers where sweat testing is performed.

\section{I d e n t i fication and Molecular Characterization of Mutations in the CFTR Gene from Classical CF}

The spectrum of mutations in CFTR gene from classical CF at PGI is listed in Table 1. In this study, 100 unrelated CF chromosomes were first analyzed for most common delta F508 mutation, which was found with $27 \%$ of $\mathrm{CF}$ chromosomes $R 117 H, R 553 X, N 1303 \mathrm{~K}$ and $G 551 D$ were identified by ARMS on a total of five chromosomes.

By restriction digestion, $3849+10 \mathrm{KbC}-$ $\mathrm{T}$ was found in $3 \mathrm{CF}$ subjects with normal sweat chloride. Using SSCP and subsequently DNA sequencing, mutations were molecularly characterized in 31 of the remaining $65 \mathrm{CF}$ chromosomes which include nine missense mutations, viz. L69H, S158N, Q493L, Y517C, V520F, I530L, S549N, E1329Q and Y1381H, one insertion mutation (1792 insA), three splice site mutations (876-6del4, 1525-1G-A, $3120+1 G-A)$, two deletion mutation $(1161 \mathrm{delC}$, $3986 \mathrm{delC}$ ), and one nonsense mutation (L218X). S549N and 1525-1G-A were the second most common mutations observed in our population (5\% each) Among them, 8 novel mutations, viz. L69H, Q493L, S158N, I530L, E1329Q, 1792 InsA and 3986-3987 delC were identified in one patient each. Notably, none of novel mutation was found in 50 control subjects.

It is noteworthy here that output productions score for 3 novel mutation $(S 158 N$, I530L and E1329Q) was found 0.05, representing deleterious effects using molecular modeling and Bioinformatics CMMB. The most common CF mutation worldwide is the deletion of a phenylalanine residue at position 508. A review of all genotyped South Asian patients showed that delta 508 is identified in $19 \%$ to $44 \%$ CF alleles (31-33), which is lower than the reported frequency of $66 \%$ worldwide $\mathrm{CF}$ population. In our study, delta F 508 represents only $27 \%$ of the analyzed and $41 \%$ of the identified $\mathrm{CF}$ allele (30). The striking characteristic of the mutation spectrum is absence of some mutations common in the Mediterranean and European population (34). S549N and 1525-1G-A were the second most common mutations, followed by $3849+10 \mathrm{kbC}$ $\mathrm{T}$. This corroborates the study of Shastri et al (35) which has recommended testing Indian CF patient for delta F508, $1161 \mathrm{delC}, 3849+10 \mathrm{kbC}$ $T$ and $S 549 N$. Absolute linkage between delta F508 and KM.19-GATT -TUB9-M470V-T854T haplotype (2-2-1-1-1) predicts a relatively recent appearance of delta F508 in Indian CF patients (28). Low frequency of delta F508 mutation and detection of eight novel and thirteen rare mutation imitate a heterogeneous spectrum of mutation in Indian CF patients. Notwithstanding, CF mutation frequencies and haplotypes vary widely among different populations and haplotype heterogeneity has been found to be greater in population with lower delta F508 frequencies (36). We documented NBD1 and NBD2 as the hotspots identified in CFTR protein in CF patients at our institute (Table 1).

\section{Identification and Molecular Characterization of Mutations in the CFTR Gene from Non-Classical CF (CAVD)}

\section{Demographics and Clinical Variables}

At our center, we used the following algorithm: male CAVD patients comprising of bilateral absence of vas deferens, unilateral absence of vas deferens, absence of epididymis, and absence of seminal vesicle as well as renal agenesis. The median age of the CAVD patients at the time of enrollment was 28 years and most of the patient consulted an urologist only after the evaluation of their female partner by a gynecologist. Semen value (1.6 \pm 0.61$)$ was much less in comparison to normal range (2-4 $\mathrm{mL})$, 
Table 1: Frequency of CFTR mutaitons identified in Indian CF Patients. Total Chromosomes100; known mutations - 66\%, unknown mutaions - $34 \%$

\begin{tabular}{|c|c|c|c|c|c|c|}
\hline S.No & Mutation & $\begin{array}{l}\text { Nucleotide } \\
\text { change }\end{array}$ & Consequence & $\begin{array}{l}\text { Exon/Int } \\
\text { ron }\end{array}$ & Domain & $\begin{array}{l}\text { Frequ } \\
\text { ency }\end{array}$ \\
\hline 1 & Delta F508 & $\begin{array}{l}\text { Deletion of } 3 \mathrm{bp} \\
(\mathrm{CTT} \text { or TTT) } \\
\text { between } 1652 \text { and } \\
1655\end{array}$ & $\begin{array}{l}\text { Deletion of Phe at } \\
508\end{array}$ & Exon 10 & NBD1 & 27 \\
\hline 2 & $1161 \mathrm{delC}$ & $\begin{array}{l}\text { Deletion of } \mathrm{C} \text { at } \\
1161\end{array}$ & Frameshift & Exon 7 & TM6 of MSD1 & 2 \\
\hline 3 & $\begin{array}{l}\text { 3986-3987 } \\
\text { delC* }\end{array}$ & $\begin{array}{l}\text { Deletion of } \mathrm{C} \text { at } \\
3986\end{array}$ & Frameshift & Exon 20 & NBD2 & 2 \\
\hline 4 & 1792ins A* & $\begin{array}{l}\text { Insertion of } A \text { at } \\
1792\end{array}$ & Frameshift & Exon 11 & NBD1 & 2 \\
\hline 5 & $\mathrm{R} 117 \mathrm{H}$ & $\mathrm{G}$ to $\mathrm{A}$ at 482 & $\begin{array}{l}\text { Argininie to } \\
\text { Histidine at } 117\end{array}$ & Exon 4 & $\begin{array}{l}\text { Extracytoplasmic loop } \\
\text { 1lindking Tm1-TM2 }\end{array}$ & 2 \\
\hline 6 & LC 9H* & T To A at 338 & $\begin{array}{l}\text { Leucine to } \\
\text { Histidine at } 70\end{array}$ & Exon 3 & NH2 terminal & 1 \\
\hline 7 & $\mathrm{~S} 158 \mathrm{~N}^{*}$ & G To A at 605 & $\begin{array}{l}\text { Serine to } \\
\text { Asparagine }\end{array}$ & Exon 4 & $\begin{array}{l}\text { Intracytoplamic loop } \\
\text { llinking TM2-TM3 }\end{array}$ & 1 \\
\hline 8 & Q493L* & A to $\mathrm{T}$ at 1609 & $\begin{array}{l}\text { Glutamine to } \\
\text { Leucine at } 493\end{array}$ & Exon 10 & NBD1 & 1 \\
\hline 9 & Y517C & A To G at 1682 & $\begin{array}{l}\text { Tyrosien to } \\
\text { Cystine at } 517\end{array}$ & Exon 10 & NBD1 & 1 \\
\hline 10 & V520F & G To T at 1690 & $\begin{array}{l}\text { Valine to } \\
\text { phenylalanine }\end{array}$ & Exon 10 & NBD1 & 1 \\
\hline 11 & G551D* & A To $\mathrm{C}$ at 1720 & $\begin{array}{l}\text { Isoleucine to } \\
\text { leucine at } 530\end{array}$ & Exon 11 & NBD1 & 2 \\
\hline 12 & S549N & G To A at 1778 & $\begin{array}{l}\text { Serine to } \\
\text { Asparagine at } 549\end{array}$ & Exon 11 & NBD1 & 5 \\
\hline 13 & G551D & $\mathrm{G}$ to $\mathrm{A}$ at 1784 & $\begin{array}{l}\text { Glycine to } \\
\text { Asparatate at } 551\end{array}$ & Exon 11 & NBD2 & 1 \\
\hline 14 & E1329Q* & $\mathrm{G}$ to $\mathrm{C}$ at 4117 & $\begin{array}{l}\text { Glutamate to } \\
\text { Glutamine at } 1329\end{array}$ & Exon 22 & NBD2 & 1 \\
\hline 15 & Y1381H & T To $\mathrm{C}$ at 4273 & $\begin{array}{l}\text { Tyrosine to } \\
\text { Histidine at } 1381\end{array}$ & Exon 23 & NBD2 & 2 \\
\hline 16 & N1303K & C To G at 4041 & $\begin{array}{l}\text { Asparagine to } \\
\text { Lysine at } 1303\end{array}$ & Exon 21 & $\begin{array}{l}\text { Extracytoplasmic loop } \\
\text { llindking Tm3-TM4 }\end{array}$ & 1 \\
\hline 17 & L218X & T To A at 785 & Leucine to stop & Exon $6 a$ & NBD1 & 1 \\
\hline 18 & R553X & $\mathrm{C}$ to $\mathrm{T}$ at 1789 & Arginine to stop & Exon 11 & - & 1 \\
\hline 19 & 876-6del4* & $\begin{array}{l}\text { Deletion of } 4 \mathrm{bp} \\
\text { TACA from } 876-4\end{array}$ & $\begin{array}{l}\text { Splice site } \\
\text { mutation }\end{array}$ & Intron $6 \mathrm{a}$ & - & 2 \\
\hline 20 & $1525-1 \mathrm{G}-\mathrm{A}$ & $\mathrm{G}$ to $\mathrm{A}$ at $1525-1$ & $\begin{array}{l}\text { Splice site } \\
\text { mutation }\end{array}$ & Intron 9 & - & 5 \\
\hline 21 & 3120+1G-A & G To A at $3120-1$ & $\begin{array}{l}\text { mRNA splicing } \\
\text { defect }\end{array}$ & Intron 16 & - & 2 \\
\hline 22 & $3849+10 \mathrm{kbC}-\mathrm{T}$ & C-T at 3849 & Exon 9 skipping & Intron 19 & - & 3 \\
\hline
\end{tabular}

* denotes novel mutation; TM- transmembrane region; MSD - Membrane spanning domain; NBD Nucleotide binding domain; Sharma et al (2008) Ann Human Genetics. 
Table 2: Spectrum of CFTR gene mutation in Indian CAVD males $(\mathbf{n}=110)$

\begin{tabular}{|c|c|c|c|c|}
\hline Mutations & $\begin{array}{l}\text { Nucleotide } \\
\text { Change }\end{array}$ & Consequences & $\begin{array}{l}\text { Exon/ } \\
\text { Intron }\end{array}$ & $\begin{array}{l}\text { No. of } \\
\text { alleles }\end{array}$ \\
\hline T5 & $\begin{array}{l}\text { Reduction of } \\
\text { oligo T tract to } \\
5 \mathrm{~T}, \mathrm{c} .1210- \\
12 \mathrm{~T}(5)\end{array}$ & Aberrant splicing & Intron 8 & 59 \\
\hline F508del & $\begin{array}{l}\text { c. } 1521 \_1523 \mathrm{del} \\
\text { CTT }\end{array}$ & Deletion of phenylalanine at 508 & Exon 11 & 26 \\
\hline p.Gly480Ser & c. $1438 \mathrm{G}>\mathrm{A}$ & Glycine to Serine at 480 & Exon 11 & 1 \\
\hline p.Arg518Lys ${ }^{\text {a }}$ & c. $1553 \mathrm{G}>\mathrm{A}$ & Arginine to Lysine at 518 & Exon 11 & 1 \\
\hline p.Arg117His & c. $350 \mathrm{G}>\mathrm{A}$ & Arginine to Histidine at 117 & Exon 4 & 7 \\
\hline p.Gly126Cys ${ }^{a}$ & c. $376 \mathrm{G}>\mathrm{T}$ & Glycine to Cystine at 126 & Exon 4 & 1 \\
\hline p.Ala141Gly ${ }^{\mathrm{a}}$ & c. $422 \mathrm{C}>\mathrm{G}$ & Alanine to Glycine at 141 & Exon 4 & 1 \\
\hline p.His139Gln ${ }^{\mathrm{a}}$ & c. $417 \mathrm{C}>\mathrm{G}$ & Histadine to Glutamine at 139 & Exon 4 & 1 \\
\hline p.Ser118Pro ${ }^{a}$ & c. $352 \mathrm{~T}>\mathrm{C}$ & Serine to Proline at 118 & Exon 4 & 1 \\
\hline p.Arg170Cys & c. $508 \mathrm{C}>\mathrm{T}$ & Arginine to Cystine at 170 & Exon 5 & 1 \\
\hline p.Glu585Gln ${ }^{\mathrm{a}}$ & c. $1753 \mathrm{G}>\mathrm{C}$ & Glutamate to Glutamine at 585 & Exon 13 & 1 \\
\hline p.Met281Arg ${ }^{a}$ & c. $842 \mathrm{~T}>\mathrm{G}$ & Methionine to Arginine at 281 & Exon 7 & 1 \\
\hline p.Arg933Thr ${ }^{a}$ & c. $2798 \mathrm{G}>\mathrm{C}$ & Arginine to Theronine at 933 & Exon 17 & 1 \\
\hline p.Ser549Asn & c. $1646 \mathrm{G}>\mathrm{A}$ & Serine to Asparagine at 549 & Exon 12 & 1 \\
\hline p.Leu69His & c. $338 \mathrm{~T}>\mathrm{A}$ & Leucine to histidine at 69 & Exon 3 & 1 \\
\hline p.Phe87Ile & c. $391 \mathrm{~T}>\mathrm{A}$ & Phenylalanine to isoleucine & Exon 3 & 1 \\
\hline p.Gly126Ser ${ }^{\text {a }}$ & c. $508 \mathrm{G}>\mathrm{A}$ & Glycine to serine at 126 & Exon 4 & 1 \\
\hline p.Phe157Cys ${ }^{\text {a }}$ & c. $602 \mathrm{~T}>\mathrm{G}$ & Phenylalanine to cystine at 157 & Exon 4 & 1 \\
\hline p.Glu543Ala ${ }^{\text {a }}$ & c. $1760 \mathrm{~A}>\mathrm{C}$ & Glutamate to alanine at 543 & Exon 11 & 1 \\
\hline p.Tyr852Phe ${ }^{\text {a }}$ & c. $2687 \mathrm{~A}>\mathrm{T}$ & Tyrosine to phenylalanine at 852 & Exon $14 a$ & 1 \\
\hline 3120 p 1 G-A & $\mathrm{G}>\mathrm{A} 3120 \mathrm{p} 1$ & Aberrant splicing & Intron 16 & 1 \\
\hline p.Pro1021Ser & c. $3193 \mathrm{C}>\mathrm{T}$ & Proline to serine at 1021 & Exon $17 a$ & 1 \\
\hline p.Asp1270Glu a & c. $3942 \mathrm{~T}>\mathrm{A}$ & Aspartate to glutamate at 1270 & Exon 20 & 1 \\
\hline
\end{tabular}

${ }^{\mathrm{a}}$ Novel mutations

Sharma et al., 2009 (Human Reproduction) \& Sharma et al., 2014 (Molecular Human Reproduction) 
however, the mean sweat chloride was in intermediate range $(40-60 \mathrm{mEq} / \mathrm{L})$. The mean serum hormone level of FSH, LH and testosterone were in normal range in CAVD patients.

\section{Spectrum of Mutations Identified in CAVD Patients}

Overall, 220 CRTR alleles were screened for mutation. We identified twenty three mutations (Table 2) (37-39). Two most common mutations, viz. p. Phe $508 \mathrm{del}$ and $p$. Arg $117 \mathrm{H}$ is were found on 26 and 7 allele, respectively. Both of these mutations were found in the heterozygous conditions in all the patients. Another most common mild form of CFTR mutation, viz. IVS8-T5 allele observed on 59 alleles in infertile CAVD males. In $13 \%$ of CAVD, the mild mutation was present in both the alleles whereas in $15 \%$ of cases, IV $58-T 5$ was detected in a compound heterozygous form with other mutation present in coding region of the CFTR. Other mutations were very rare. Among them, fourteen mutations were novel. All these novel mutations were subjected for determination of prediction score using SIFT (http://blocks.fh crc.org/sift/SIFT.html) and confirmed by polyphen-2 (http//genetics.bwh. harvard.edu/php). Threshold for pathological mutations was 0.05. Among them, Gly126Cys, Ser118Pro, Met281Arg, Arg933Thr, Lys69His, Glu543Ala and Asp1270Glu were damaging mutation, which can perturb the protein structure (37-39).

Genetic analysis of the CFTR gene led to identification of the mutations in $81 \%$ of the Indian CAVD males and this detection was very similar to that of Caucasians, however, the spectrum of mutation in this study was different from that Caucasians (40-41). Notably, the allele frequency of $p$. Phe $508 \mathrm{del}$ mutation in our population is similar to that of France (4) and Spain (5). The 5T allele in our population was found with an allele frequency of $28 \%$ is very similar to that of Canada, Brazil $(42,43)$.

\section{Association of Cystic Fibrosis Genetic Modifiers with Congenital Bilateral Absence of the Vas Deferens}

To investigate whether genetic modifiers of CF lung disease also predispose to CAVD in association with CFTR mutations, we tested the hypothesis that polymorphisms of TGF- $\beta 1$ and EDNRA polymorphism might play a role in penetrance of CAVD. These polymorphisms have been reported to modify CF lung disease, and might also contribute as genetic modifiers of CAVD. Sixty CAVD subjects and fifty controls were investigated for candidate polymorphism $T G F-\beta 1$ or EDNRA associated with a more serve lung phenotype among CF disease. Importantly, CC genotype (SNP r5335) of EDNRA and TT genotype (SNP r51982073) TGF- $\beta 1$ were associated with CAVD to occur more frequently among CF individuals (37). TGF- $\beta 1$ is the best described modifier of $\mathrm{CF}$ associated with pulmonary phenotype. In reference to our study, the human vas deferens, epididymis and seminal vesicles develop from the Wolffian duct. Notably, TGF- $\beta 1$ and related signaling pathways play an important role in normal Wolffian duct development and differentiation $(44,45)$. On the other hand, other modifier of CF lung disease (EDNRA) is also associated with CAVD.

EDNRA has been implicated in normal formation of mammalian nervous system, the anorectum, and craniofacial structures such as mandible (46-48). EDNRA plays an important role during development of the vas deferens which could be due to loss of the vas in the setting of CFTR insufficiency. This is the first study in reference to the Indian population where we identify possible involvement of these pathways in an atypical CF- related condition, namely CAVD. Recently, it has been documented TGF- $\beta 1$ receptor and P 38 MAPK signaling reduce CFTR activity and probably enhance the effect associated with heterogeneous CFTR mutations and may result in male infertility (49). 
Functional Characterization and Pharmacological Correction of Novel and Rare Mutations

The striking characteristic of the identified mutations at our center were the presence of severe rare mutations but the absence of the most common mutations identified in the Mediterranean and European population, which clearly represented the heterogeneous spectrum of CFTR mutations at our Institute. These rare mutations are called orphan mutation because of their very low incidence. Moreover, rare familiar mutations cannot provide sufficient information on the phenotype due to these mutations, viz. $L 69 H$, F87I, S118P, G126S, H139Q, F157C, F494L, $E 543 A, S 549 N, Y 852 F$ and D1270E from both classical CF patients and CAVD patients (40). It is noteworthy here that the cellular and function data on these mutations can improve CF genetic counseling. For functional characterization and therapeutic implications for these CF rare mutations, baby hamster kidney cells are an adherent cell line used for this study (50). Functional findings revealed that $\mathrm{L} 69 \mathrm{H}$ was found as a novel class II CF mutation. The trafficking to the plasma membrane of $\mathrm{L} 69 \mathrm{H}-$ CFTR is abnormal as corroborated by western blot analysis. Further confocal microscopic imaging showed the abundance of L69H mutated CFTR protein in the endoplasmic reticulum and absence on the plasma membrane. In view of above finding, the processing pathway of this variant is similar to that of F508 del-CFTR mutation which is the most common mutation worldwide. Misfolded F508 delCFTR is retained by the ER and undergoes ubiquitination, thereby accelerating its proteome degradation and reducing F508 del-CFTR trafficking in the plasma membrane $(51,52)$. The model of 3D structure of CFTR which is predicted using the Sav1866 experimental 3D structure. $\mathrm{L} 69 \mathrm{H}$ is studied in a short cytosolic $\alpha-$ helix in the N-terminus of CFTR preceding the first transmembrane helix TMI of MSD that is called "elbow helix", which is conserved feature among the ABC exporter family. Possibly, L69H mutation may perturb the network formed hydrophobic side chains of the cytosolic extension of MSD1TMI helices. MSDI-NBDI linker (1368) might thus play an important role for MSD1 folding and destabilization of this domain at the membrane. Another important S549N located in the LSGGQ signature motif of NBD1 and may alter the hydrolysis of ATP to regulate channel activity (53) as a result S549N classified as class III CF mutation (54). Normal maturation of S459 N-CFTR protein was observed in our study as reported by others (54). Further, the study was conducted to evaluate the effect of some potentiator viz Miglustat, Isolab and VX-809 to increase the activity of defective CFTR protein due to presence of these mutations. Ivacaftor (VX-770) is an investigational, orally bioavailable agent which was shown to augment the chloride transport activity of G551D-CFTR protein in vitro (54). In our study, the pharmacological corrector VX809 was found to activate $\mathrm{L} 69 \mathrm{H}$ in BHK-21 cells in similar to that of delta F508 (50). The activation of L69H and delta F508 were both significantly corrected in terms of maturation and translocation of CFTR protein to cell membrane when cells were treated with VX809 potentiator. Whereas, S549N mutation classify as type III mutation was also corrected as its translocation to plasma membrane (50). It is noteworthy here that VX809 molecule is FDA approved, so that this potentiator can be used as a therapeutic molecule to rescue from type II and III mutations associated with Indian CF patients.

\section{Current Progress in Treatment of Basic Defects in CF}

CFTR modulator therapies have been directed towards specific disease causing mutations and the molecules pathways that underlie these causes. CFTR mutations grouped into conservative classes have led to the development of specific approaches towards treating the molecular effect in CF (Table 3) (5558). Non-sense mutations in CFTR have been shown to be rescued with application of a compound ataluren, derived from 
Table 3: CFTR based therapies completed or in progress towards treating the basic defect in $\mathrm{CF}$

\begin{tabular}{|l|l|l|l|}
\hline CFTR mutation & $\begin{array}{l}\text { Mutation } \\
\text { Frequency }(\%)\end{array}$ & Therapeutic approach & Status \\
\hline G551D/other & 4 & Ivacaftor & FDA approved \\
\hline $\begin{array}{l}\text { Non-G551D } \\
\text { gating/other }\end{array}$ & 1 & Ivacaftor & Phase II/III \\
\hline R11 7H/other & 5 & Ivacaftor & Phase III \\
\hline$\triangle$ F508/ $\triangle$ F508 & 49 & $\begin{array}{l}\text { Lumacaftor+ivacaftor } \\
\text { VX-661+ivacaftor }\end{array}$ & $\begin{array}{l}\text { phase III planned } \\
\text { Phase II }\end{array}$ \\
\hline PTC/other & 10 & Ataluren & Phase III \\
\hline
\end{tabular}

aminoglycoside antibiotic that can induce readthrough of premature termination codons. This investigational drug is in phase III clinical trial (55). Two new molecules have been developed for correction, VX809 and potentiator, VX770, of the delta F508 mutations. Some of class III mutants respond to VX770 by increasing the chlorides transport. CFTR potentiator Ivacaflor (Kalydeco, VX-770, vertex pharmaceuticals, Boston, MA, USA) FDA and European regulatory authorities approved drug to treat $\mathrm{CF}$ patient with a class III G551D mutation (56-58). Recent advances of targeted molecular therapies and high throughput screening have resulted in multiple drug therapies that target many important mutations in the CFTR protein (59).

In summary, these findings represent an important milestone in the development of treatments designed to improve CFTR protein function as a means of addressing the underlying cause of cystic fibrosis.

\section{Future Directions}

In Indian scenario, the diagnosis of $\mathrm{CF}$ is important since sweat chloride measurement using pilocarpine iontophoresis is limited to only few centers despite a large population in this country. Sweat chloride measurement technique facility is must at every district level to pick up the CF population. The most reliable is the sweat induction by pilocarpine iontophoresis, followed by sweat chloride collection on a gauze or filter paper. Sweat chloride concentration in the $\mathrm{CF}$ patient is in intermediate range. In these cases, gene sequencing is essential to provide positive $\mathrm{CF}$ diagnosis as well as, mutations specific therapies which have become available recently $(59,60)$.

Other mechanisms of corrector therapy are being developed. Recently, the direct and indirect modulation of the nitric oxide (NO) pathway has been investigated as a possible corrector mechanism in delta F508-CFTR (58, $59)$. If future drug combinations are sufficiently robust to correct CFTR function in individuals with only one copy Phe508 del, this modulator will ideally provide clinical benefit to over $90 \%$ of all patients with CF. Thus, other approaches such as drugs that read through premature stop mutation and gene replacement or editing must continue (61).

\section{Acknowledgement}

I am thankful to Prof. M. Singh, Prof. B. R. Thapa, Advance Pediatric Centre, PGIMER, Chandigarh, and Prof. S. K. Singh, Deptt. of Urology, PGIMER, Chandigarh who provided classical and non-classic form of $\mathrm{CF}$ patients. I am also thankful to Prof. Frederic Becq, Laboratoire Signalisation et Transports Ioniques Membranaires, Universite de Poitiers, CNRS, Poitiers France, who provided the facilities to carry out the work on functional characterization of novel mutations and use of potentiatore as 
therapeutic molecular. We are also thankful to Department of Science and Technology, New Delhi, and Indian Council of Medical Research, New Delhi as well as Charpak, Fellowship of France in India provided the funding to carry out this research work.

\section{References}

1. Castellani C, Picci L, Tamanini A, Girardi P, Rizzotti P, Assael BM (2009). Association between carrier screening and incidence of cystic fibrosis. JAMA 302: 2573-2579.

2. Prasad R, Sharma H, Kaur G (2010). Molecular basis of cystic fibrosis disease: an Indian perspective. Indian $\mathrm{J}$ Clin Biochem 25: 335-341.

3. Bhakoo ON, Kumar R, Walia BNS (1968). Mucoviscidosis of the lung. Report of a case. Indian J Pediatr 35:183-185.

4. Prasad R, Marwaha RK, Kaur G, Walia BNS (1998). Spectrum of biochemical genetic diseases in North India. Med Sci Res 26: 455-456.

5. Rowe SM, Miller S, Sorscher EJ (2005). Cystic fibrosis. $N$ Engl J Med 352: 19922001.

6. Chillon M, Casals $\mathrm{T}$, Mercier B, et al (1995). Mutations in the cystic fibrosis gene in patients with congenital absence of the vas deferens. $N$ Engl J Med 332: 14751480 .

7. Riordan JR, Rommens JM, Kerem B, et al (1989). Identification of the cystic fibrosis gene: cloning and characterization of complementary DNA. Science 245: 10661073.

8. Rommens JM, Iannuzzi MC, Kerem B, et al (1989). Identification of the cystic fibrosis gene: chromosome walking and jumping. Science 245: 1059-1065.

9. Zielenski J, Rozmahel R, Bozon D, et al (1991). Genomic DNA sequence of the cystic fibrosis transmembrane conductance regulator (CFTR) gene. Genomics 10: 214228.

10. Bear CE, Li CH, Kartner N, et al (1992). Purification and functional reconstitution of the cystic fibrosis transmembrane conductance regulator (CFTR). Cell $\mathbf{6 8}$ : 809-818.

11. Hyde SC, Emsley P, Hartshorn MJ, et al (1990). Structural model of ATP-binding proteins associated with cystic fibrosis, multidrug resistance and bacterial transport. Nature 346: 362-365.

12. Short DB, Trotter KW, Reczek D, et al (1998). An apical PDZ protein anchors the cystic fibrosis transmembrane conductance regulator to the cytoskeleton. $J$ Biol Chem 273: 19797-19801.

13. Castellani C, Cuppens H, Macek M Jr, et al (2008). Consensus on the use and interpretation of cystic fibrosis mutation analysis in clinical practice. JCyst Fibros 7: 179-196.

14. Haardt M, Benharouga M, Lechardeur D, Kartner N, Lukacs GL (1999). C-terminal truncations destabilize the cystic fibrosis transmembrane conductance regulator without impairing its biogenesis. A novel class of mutation. $J$ Biol Chem 274: 21873 21877.

15. Anguiano A, Oates RD, Amos JA, et al (1992). Congenital bilateral absence of the vas deferens. A primarily genital form of cystic fibrosis. JAMA 267: 1794-1797.

16. Chillón M, Casals $\mathrm{T}$, Mercier B, et al (1995). Mutations in the cystic fibrosis gene in patients with congenital absence of the vas deferens. $N$ Engl $J$ Med 332: 14751480 .

17. Drumm ML, Konstan MW, Schluchter MD, et al (2005). Genetic modifiers of lung disease in cystic fibrosis. $N$ Engl J Med 353: 1443-1453.

18. Darrah R, McKone E, O'Connor C, et al 
(2010). EDNRA variants associate with smooth muscle mRNA levels, cell proliferation rates, and cystic fibrosis pulmonary disease severity. Physiol Genomics 41: 71-77.

19. Goraca A (2002). New views on the role of endothelin (minireview). Endocr Regul 36: 161-167.

20. Solomon GM, Marshall SG, Ramsey BW, Rowe SM (2015). Breakthrough therapies: Cystic fibrosis (CF) potentiators and correctors. Pediatr Pulmonol 50: S3-S13.

21. Morral N, Nunes V, Casals T, et al (1993). Microsatellite haplotypes for cystic fibrosis: mutation frameworks and evolutionary tracers. Hum Mol Genet 2: 1015-2102.

22. Dodge JA (2015). A millennial view of cystic fibrosis. Dev Period Med 19: 9-13.

23. Farrell PM, Rosenstein BJ, White TB, et al (2008). Guidelines for diagnosis of cystic fibrosis in newborns through older adults: Cystic Fibrosis Foundation consensus report. J Pediatr 153: S4-S14.

24. Rosenstein BJ, Cutting GR (1998). The diagnosis of cystic fibrosis: a consensus statement. Cystic Fibrosis Foundation Consensus Panel. J Pediatr 132: 589-595.

25. Gibson LE, Cooke RE (1959). A test for concentration of electrolytes in sweat in cystic fibrosis of the pancreas utilizing pilocarpine by iontophoresis. Pediatrics 23: 545-549.

26. Rowe MS, Miller SBS, Sorcher EJ (2005). Cystic Fibrosis. N Engl J Med 352: 19912001.

27. Wallis C (1997). Diagnosing cystic fibrosis: blood, sweat, and tears. Arch Dis Child 76: 85-88.

28. Veeze HJ, Sinaasappel M, Bijman J, Bouquet J, de Jonge HR (1991). Ion transport abnormalities in rectal suction biopsies from children with cystic fibrosis.
Gastroenterology 101:398-403.

29. Walters MP, Kelleher J, Gilbert J, Littlewood JM (1990). Clinical monitoring of steatorrhoea in cystic fibrosis. Arch Dis Child 65: 99-102.

30. Sharma N, Singh M, Kaur G, Thapa BR, Prasad R (2009). Identification and characterization of CFTR gene mutations in Indian CF patients. Ann Hum Genet 73: 2633.

31. Bowler IM, Estlin EJ, Littlewood JM (1993). Cystic fibrosis in Asians. Arch Dis Child 68: 120-122.

32. Kabra M, Kabra SK, Ghosh M, et al (2000). Is the spectrum of mutations in Indian patients with cystic fibrosis different? $\mathrm{Am} \mathrm{J}$ Med Genet 93: 161-163.

33. Mei-Zahav M, Durie P, Zielenski J, et al (2005). The prevalence and clinical characteristics of cystic fibrosis in South Asian Canadian immigrants. Arch Dis Child 90: 675-679.

34. Morral N, Nunes V, Casals T, et al (1993). Microsatellite haplotypes for cystic fibrosis: mutation frameworks and evolutionary tracers. Hum Mol Genet 2: 1015-1022.

35. Shastri SS, Kabra M, Kabra SK, Pandey RM, Menon PS (2008). Characterisation of mutations and genotype-phenotype correlation in cystic fibrosis: experience from India. J Cyst Fibros 7: 110-115.

36. Kilinç MO, Ninis VN, Dağli E, et al (2002). Highest heterogeneity for cystic fibrosis: 36 mutations account for $75 \%$ of all CF chromosomes in Turkish patients. Am $J$ Med Genet 113: 250-257.

37. Sharma H, Mavuduru RS, Singh SK, Prasad R (2014). Heterogeneous spectrum of mutations in CFTR gene from Indian patients with congenital absence of the vas deferens and their association with cystic fibrosis genetic modifiers. Mol Hum Reprod 
20: $827-835$.

38. Sharma N, Singh M, Acharya N, et al (2008). Implication of the cystic fibrosis transmembrane conductance regulator gene in infertile family members of Indian CF patients. Biochem Genet 46: 847-856.

39. Sharma N, Acharya N, Singh SK, Singh M, Sharma U, Prasad R (2009). Heterogenous spectrum of CFTR gene mutations in Indian patients with congenital absence of vas deferens. Hum Reprod 24: 1229-1236.

40. Casals T, Bassas L, Egozcue S, et al (2000). Heterogeneity for mutations in the CFTR gene and clinical correlations in patients with congenital absence of the vas deferens. Hum Reprod 15: 1476-8143.

41. Castellani C, Cuppens H, Macek M Jr, et al (2008). Consensus on the use and interpretation of cystic fibrosis mutation analysis in clinical practice. J Cyst Fibros 7: 179-196.

42. Mak V, Zielenski J, Tsui LC, et al (1999). Proportion of cystic fibrosis gene mutations not detected by routine testing in men with obstructive azoospermia. J Am Med Assoc 281: 2217-2224.

43. Berinardino ALF, Lima CA, Zatz M (2003). Analysis of mutation in the cystic fibrosis transmembrane conductance regulator (CFTR) gene in patients with obstructive azoospermia. Genet Mol Biol 26: 1-3.

44. Blobe GC, Schiemann WP, Lodish HF (2000). Role of transforming growth factor beta in human disease. $N$ Engl J Med 342: 1350-1358.

45. Hocher B, Schwarz A, Fagan KA, et al (2000). Pulmonary fibrosis and chronic lung inflammation in ET-1 transgenic mice. Am JRespir Cell Mol Biol 23: 19-26.

46. Ruest LB, Xiang X, Lim KC, Levi G, Clouthier DE (2004). Endothelin-A receptor -dependent and -independent signaling pathways in establishing mandibular identity. Development 131: 4413-4423.

47. Pla P, Larue L (2003). Involvement of endothelin receptors in normal and pathological development of neural crest cells. Int J Dev Biol 47: 315-325.

48. Moore SW, Zaahl MG (2007). Association of endothelin-beta receptor (EDNRB) gene variants in anorectal malformations. $J$ Pediatr Surg 42: 1266-1270.

49. Yi S, Pierucci-Alves F, Schultz BD (2013). Transforming growth factor- $\beta 1$ impairs CFTR-mediated anion secretion across cultured porcine vas deferens epithelial monolayer via the p38 MAPK pathway. $\mathrm{Am}$ J Physiol Cell Physiol 305: C867-C876.

50. Sharma H, Jollivet Souchet M, Callebaut I, Prasad R, Becq F (2015). Function, pharmacological correction and maturation of new Indian CFTR gene mutations. $J$ Cyst Fibros 14: 34-41.

51. Cheng SH, Gregory RJ, Marshall J, et al (1990). Defective intracellular transport and processing of CFTR is the molecular basis of most cystic fibrosis. Cell 63: 827834.

52. Ward CL, Omura S, Kopito RR (1995). Degradation of CFTR by the ubiquitinproteasome pathway. Cell 83: 121-127.

53. Ramsey BW, Davies J, McElvaney NG, et al (2011). A CFTR potentiator in patients with cystic fibrosis and the G551D mutation. NEngl J Med 365: 1663-1672.

54. Yu H, Burton B, Huang CJ, et al (2012). Ivacaftor potentiation of multiple CFTR channels with gating mutations. $J$ Cyst Fibros 11: 237-245.

55. Wilschanski M, Miller LL, Shoseyov D, et al (2011). Chronic ataluren (PTC124) treatment of nonsense mutation cystic fibrosis. Eur Respir J 38: 59-69.

56. Rowe SM, Borowitz DS, Burns JL, et al (2012). Progress in cystic fibrosis and the 
CF Therapeutics Development Network. Thorax 67: 882-890.

57. Okiyoneda T, Veit G, Dekkers JF, et al (2013). Mechanism-based corrector combination restores $\triangle$ F508-CFTR folding and function. Nat Chem Biol 9: 444-454.

58. Ramsey BW, Davies J, McElvaney NG, et al (2011). A CFTR potentiator in patients with cystic fibrosis and the G551D mutation. NEnglJ Med 365: 1663-1672.
59. Solomon GM, Marshall SG, Ramsey BW, Rowe SM (2015). Breakthrough therapies: Cystic fibrosis (CF) potentiators and correctors. Pediatr Pulmonol 50: S3-S13.

60. De Boeck K, Vermeulen F, Dupont L (2017). The diagnosis of cystic fibrosis. Presse Med 46: e97-e108.

61. Fajac I, Wainwright CE (2017). New treatments targeting the basic defects in cystic fibrosis. Presse Med 46: e165-e175. 